\title{
Developing Software and Systems Engineering Standards
}

\author{
Rory V. O'Connor
}

\begin{abstract}
There are a great many Software and Systems Engineering standards such as those supported by organizations like the ISO (International Organization for Standardization). It is often said that many of these have a poor reputation with many sections of academia and industry. Whilst there may be many publicized business advantages of using standards, standardization is an often-neglected route for exploiting academic and commercial research. Often researchers have little experience of standardization to plan, implement and exploit their research utilizing standards. Involvement with standards development organizations in your research can positively increase international recognition and highlight in a world stage your research and enhance your international reputation. This keynote address examined the benefits of being directly involved in the standards community for both industry and academia and specifically how standards can inform your research. Based upon personal experience as Ireland Head of Delegation to ISO's Software and Systems Engineering group and that of being an ISO standards editor, this keynote will examine the issues and benefits of becoming actively involved inside the standardization community and how this can be translated into your personal research agenda.
\end{abstract}

Key words: Computer Systems and Technologies, International Standards, ISO.

\section{INTRODUCTION}

Standards are an important feature of modern life. They have been fundamental both in the development of the global economy and in the development of complex modern technologies. Although not a recognized engineering profession, the discipline called "software engineering" is evolving toward professional acceptance. One element of this evolution is the creation of a body of standards for the responsible practitioners. This article describes those standards [1]. International standards may serve to reduce information costs and, thereby, increase trade [2]. Moreover, international standard certification is sometimes a regulatory requirement, particularly when trading in the EU. It has also been argued that international standards can reduce any competitive disadvantage associated with other sources of reputation, such as country of origin. A World Bank [3] report states: "To expand their trade, countries also need good standards, measurement, testing, and quality control systems". These constitute the infrastructure for technical activity, and their significance grows as traded products and services increasingly have to conform to world standards and regulation [4].

\section{History of International Standards}

International standardization began in the electrotechnical field when the International Electrotechnical Commission (IEC) was established in 1906 [5]. The International Federation of the National Standardizing Associations (ISA) was then set up in 1926 to create standards in the field of mechanical engineering. Four years after ISA was dissolved in 1942, delegates from 25 countries decided to create a new international organization, ISO (International Organization for Standardization), "to facilitate the international coordination and unification of industrial standards" [5]. Since its creation, ISO has experienced three major turning points. For its first 40 years, ISO followed its initial mission, focusing on technical standards for specific products or technologies such as screws, sizing systems for clothing and shoes, and laser technology. The organization's first turning point came in the 1980s when ISO delved into the development of "process" standards, specifically the ISO 9000 Quality Management System standards. The creation of generic management standards that could cover almost any industry sector was a notable departure from the product/industry/technology-specific nature of previous ISO standards. The ISO 9000 series became ISO's most widely known and successful (measured by sales) standards ever, with more than half a million organizations adopting them globally. 
ISO's evolution continued with another turning point a decade later. In 1993, with the creation of ISO/TC 207 to develop the ISO14000 Environmental Management standards, ISO took its most notable step into the public policy arena, extending its influence beyond industry and their customers, and into issues of general public interest.

ISO's third transition is presently taking place in the form of the organization's current (and accelerating) pursuit of the development of standards that directly support and advance sustainable development. Six decades after its creation, ISO has grown into the world's largest and most widely recognized standards development organization. ISO's influence is exercised not solely through its size and popularity, but also because of the status of its outputs as the world's "trade-legal" standards as recognized by the World Trade Organization (WTO). Once nationalized, these international standards can become market requirements (even for companies without foreign operations), for instance, as part of government procurement criteria, as has happened in the case of the ISO 9000 and ISO 14000 series standards. There is, therefore, little doubt that any new ISO standards in the social or environmental field can and will have a sizable influence on businesses, governments, and civil society around the world.

Currently ISO has members from 162 countries and 3,368 technical bodies to take care of standard development. The ISO has published more than 19,500 International Standards covering almost every industry, from technology, to food safety, to agriculture and healthcare.

\section{Software Engineering and Standards}

Professor Francois Coallier the current chairperson of ISO/IEC JCT1/SC7 Software and Systems Engineering Technical Committee considers that the relationship between engineering and standards should now be obvious [6]. Because standards facilitate reuse and, usually, document proven and generally acceptable practices, they are an intimate part of every engineer's professional practice. Standards also constitute a significant part of an engineer's teaching and training curriculum.

In software engineering, the relationship with standards goes deeper. While the foundations of software engineering include fields such as computer science, systems engineering, and project management, standards have played a significant role in the development and codification of this rather young engineering discipline.

The US National Bureau of Standards published the first software engineering standard barely eight years after the term 'software engineering' was coined in 1968. The same year this standard was published, the IEEE created its software engineering standards committee. In 1987, the joint ISO and IEC standard subcommittee (ISO/IEC JTC 1/SC7, or SC7) was then created. As of August 2015 there are 155 published SC7 standards, designed by 40 'participating countries', with the cooperation of a further 20 'observing countries'. These standards are still evolving, with new ones being elaborated that cover new areas on a continuous basis.

\section{STANDARDS IN DETAIL}

This section will explore in more detail what are standards, what are the benefits of using standards and the drawbacks of standards.

\section{What are Standards?}

Standards are published documents that establish specifications and procedures designed to maximize the reliability of the materials, products, methods, and/or services people use every day [7]. Standards address a range of issues, including but not limited to various protocols to help maximize product functionality and compatibility, facilitate interoperability and support consumer safety and public health.

Standards form the fundamental building blocks for product development by establishing consistent protocols that can be universally understood and adopted. This helps fuel compatibility and interoperability and simplifies product development, and 
speeds time-to-market. Standards also make it easier to understand and compare competing products. As standards are globally adopted and applied in many markets, they also fuel international trade.

It is only through the use of standards that the requirements of interconnectivity and interoperability can be assured. It is only through the application of standards that the credibility of new products and new markets can be verified. In summary standards fuel the development and implementation of technologies that influence and transform the way we live, work and communicate.

\section{Benefits of International Standards}

International Standards bring technological, economic and societal benefits. They help to harmonize technical specifications of products and services making industry more efficient and breaking down barriers to international trade. Conformity to International Standards helps reassure consumers that products are safe, efficient and good for the environment. For business International Standards are strategic tools and guidelines to help companies tackle some of the most demanding challenges of modern business. They ensure that business operations are as efficient as possible, increase productivity and help companies access new markets.

From a governmental perspective, nations can draw on international expertise and experience and are therefore a vital resource for governments when developing public policy, where for example, national governments can use standards to support public policy when developing market regulations for the benefit of its citizens. By integrating standards into national regulation, governments help to ensure that requirements for imports and exports are the same the world over, therefore facilitating the movement of goods, services and technologies from country to country.

\section{Drawbacks of International Standards}

Parts of the software and IT engineering community harbor many misconceptions associated with standards, especially process standards. The most common are that standards are rigid, obsolete, and plain boring. Standards are also perceived as being the antithesis of agility. For example, in the field of software process standards studies done by $[8,9,10,11]$ have shown that this negative perception on the software process model is driven by a negative view of cost, documentation and bureaucracy. However, a positive counter-point exists where studies such as [12, 13, 14, 15] have shown that attitudes and sentiment towards such standards is positive and increasing.

\section{HOW ARE STANDARDS CREATED}

The process of developing a standard is typically facilitated by a Standards Development Organization (SDO), which adheres to fair and equitable processes that ensure the highest quality outputs and reinforce the market relevance of standards. SDOs, such as IEEE, IEC, ISO, and others, offer time-tested platforms, rules, governance, methodologies and even facilitation services that objectively address the standards development lifecycle, and help facilitate the development, distribution and maintenance of standards [7]. While the goals of each SDO are essentially the same, each SDO applies its own rules, processes, and terminology to the standards development process. Typically, each SDO is comprised of Boards, Committees and staff who establish and maintain the policies, procedures and guidelines that help ensure the integrity of the standards development process, and the standards that are generated as an outcome of this process.

\section{How does ISO develop standards?}

An ISO standard is developed by a panel of experts, within a technical committee. Once the need for a standard has been established, these experts meet to discuss and negotiate a draft standard. As soon as a draft has been developed it is shared with ISO's members who are asked to comment and vote on it. If a consensus is reached the draft 
becomes an ISO standard, if not it goes back to the technical committee for further edits [16]. Essentially the ISO follows a six-step process:

1. Proposal - A new work item proposal (NP) is submitted for vote by members of the relevant committee. A project leader is appointed.

2. Preparatory - Working group is set up. Successive working drafts are considered until the group is satisfied it has the best solution to the problem. The draft is forwarded to the working group's parent committee.

3. Committee - A first committee draft is registered by the ISO Central Secretariat. It is distributed for comment and voting. Successive drafts may be considered until consensus is reached and the text is then finalized for submission as a draft International Standard (DIS).

4. Enquiry - Draft International Standard (DIS) is circulated for comment and voting. Its approved as a final draft International Standard (FDIS) if a two-thirds majority are in favor and not more than one-quarter of the total number of votes cast are negative.

5. Approval - A final draft International Standard (FDIS) is circulated to all ISO member bodies. It's approved as an International Standard if a two-thirds majority of members are in favor and not more than one-quarter of the total number of votes cast are negative.

6. Publication - Once a final draft International Standard has been approved, the final text is sent to the ISO Central Secretariat to publish the International Standard

The key principles in ISO standards development are:

- ISO standards respond to a need in the market - ISO does not decide when to develop a new standard, but responds to a request from industry or other stakeholders such as consumer groups. Typically, an industry sector or group communicates the need for a standard to its national member who then contacts ISO.

- ISO standards are based on global expert opinion - ISO standards are developed by groups of experts from all over the world, that are part of larger groups called technical committees. These experts negotiate all aspects of the standard, including its scope, key definitions and content.

- ISO standards are developed through a multi-stakeholder process - The technical committees are made up of experts from the relevant industry, but also from consumer associations, academia, NGOs and government.

- ISO standards are based on a consensus - Developing ISO standards is a consensus-based approach and comments from all stakeholders are taken into account.

For illustrative purposes to understand an insider view of the development of international standards see example see examples published in the literature such as [17, $18,19,20]$ for firsthand account from those involved in ISO standards development in the field of software an systems engineering.

\section{WHO CREATES STANDARDS}

The typical stakeholders active in the development of International Standards are: Industry covering utilities, manufacturers, installers, suppliers etc. either at the company level or via trade associations, consortia, etc.; Consumers normally organized at the national, regional or international level; Academia - universities and research institutes; Test laboratories; and Governments and regulators. It is essential that all of the interested parties in the value chain are represented and active in the development of International Standards to ensure that the final deliverables correspond to market needs and fulfill user expectations. 
Ideally a standard is a collective work with representatives of organizations having an interest and expertise in the subject matter are brought together by a Standards Development Organization to form a technical committee or working group to draw up the standard. Typically such working groups are open groups. They are comprised of individuals for individual standards projects or representatives from entities (such as corporations, government agencies or academic institutions) for corporate standards projects. All participating in working groups have technical expertise, knowledge and dedicated interest in the technology being standardized in the standard. It is common that such working groups meet and make technical decisions in the process of developing standards. Those participating in working groups have strong technical knowledge and expertise in the subject matter of the standard project, and understand and respect diverse points of view. Individuals and corporations in working groups work collaboratively to reach consensus in order to move the project to sponsor ballot and ultimately approval stage by the Standards Development Organization. There is a range of Standards Development Organization and here we will focus on ISO.

\section{Who develops ISO standards?}

ISO standards are developed by groups of experts, within technical committees (TCs). TCs are made up of representatives of industry, NGOs, governments and other stakeholders, who are put forward by ISO's members. Each TC deals with a different subject, for example there are TCs focusing on screw threads, shipping technology, food products and many, many more. Currently ISO has over 250 technical committees.

The best opportunity to influence ISO's technical work is offered by direct participation in technical committees, subcommittees and working groups. As a member of a committee, delegates can input the views of the national stakeholders they represent and can pro- pose new projects and nominate project leaders. Individuals may contribute to the work of a committee in various ways: as experts, especially in working groups, or as heads or members of national delegations.

\section{Why get involved in standards development?}

One of the strengths of ISO standards is that they are created by the people that need them. Industry and academic experts drive all aspects of the standard development process, from deciding whether a new standard is needed to defining all the technical content. Getting involved in standards development brings your concerns and needs to bear on a process that will affect you in the future. Getting involved in this process can bring significant advantages to commercial organizations such as: Giving early access to information that could shape the market in the future; Giving your company a voice in the development of standards; and Helping to keep market access open. However an oftenoverlooked aspect of involvement in the development of standards is the potential benefits to researcher and academic career development.

\section{ISO Standards and Academica}

Whilst many participants in standards development activities are representatives of industry organizations of industry representative groups, there are a growing number of academics involved in standards development. For such academics there are many potential professional and career advantages, in particular in relation to research activities. Based on personal experience this author has found involvement in standardization development to be a fruitful area for research, both in of the design and development of standards (such as in [21, 22]) and the usage and experimentation with standards in case studies (such as [23, 24]) and commercial settings (such as [25, 26]). Furthermore, activate participation in standards development committees and working groups provides direct access to researchers to key individuals and organizations that can provide valuable potential research partners.

There are many ways to use standards or standardization in research. Ultimately, the most effective way to include standards and standardization in your research project is to 
make your national standards body a part of your research project. There are many arguments as to why using existing standards or even shaping future standards will benefit researchers and research projects:

- Using standards as a knowledge source in the earliest possible stages of your research and innovation avoids duplication of work and places your contribution on a broad and marketable basis.

- Building upon standards ensures compliance with market conditions and increases the transparency for prospective customers.

- Being involved in standardization and shaping future standards helps to translate your research and innovation findings, including intellectual property rights, into marketable solutions. This aspect has been recognized by the European Commission with Horizon 2020.

- Addressing standardization as part of your dissemination strategy can help win funding for your research and innovation. In parallel, monitoring or even influencing future standards might lower your future R\&D risks and costs.

Effectively disseminating research results will become even more important in the future. Firstly, Europe's future is connected to its power to innovate. Research outcomes have to lead to innovative products and services. Secondly, the complexity and interdisciplinary of today's products and services is constantly rising. Thirdly, customers expect new and innovative solutions after increasingly shorter periods of time.

For all these reasons standards come into play as they speed up the access to market. Some practical examples of the fruitful interaction between research and standardization are available online. Being part of the standardization community allows you to interact with key stakeholders and market players, and acquire knowledge you might not gain outside of this community. Participating in standardization, increases your visibility and you will be part of a recognized and reputable worldwide platform.

\section{FINAL REMARKS}

According to [27] interest in standardization education is growing. In Indonesia, for instance, the number of universities cooperating with the Indonesian national standards body BSN to address standardization has increased from none in 2007 to 23 in 2010. South Korea is at the forefront of implementing standardization education in academic curricula and does more than Europe as a whole [28]. Standardization education is emerging in other Asian countries as well, both at the academic level and at lower levels including secondary and even elementary schools. Standardization education increases awareness of standards and standardization and prepares people for jobs in which they have standards-related tasks. Many of today's students will become the decision-makers of tomorrow so it is important that they are aware of the benefits of standardization. The IEC is eager to promote the value of standardization and its related activities within academic institutions and at the same time encourages them to participate in the IEC's work through their National Committee.

In the past years the role of standardization as a bridge between research activities and the market has been increasingly recognized, both by EU institutions and by R\&D stakeholders.

The European framework programme for R\&D, Horizon 2020, focuses on market take-up of research results and innovation. Standardization is identified in Horizon 2020 as one of the measures that will support this. "Stronger support will be given to the market take-up of innovation, including by the public sector. This will involve a better use of the potential of research infrastructures, as well as setting technical standards, precommercial procurement and strengthened loan and equity financing". 
This growing relevance of standardization in the context of research projects is demonstrated by the growing number of call topics in which a reference to standardization is made.

\section{REFERENCES}

[1] Moore, J, W. Software engineering standards. John Wiley \& Sons, Inc., 1998.

[2] Swann, G. International standards and trade: A Review of the Empirical Literature, Organisation for Economic Co-operation and Development, 2010.

[3] World Bank, World Development Report: Knowledge for Development. Oxford, UK, Oxford University Press, 1999.

[4] Hudson, J., and Orviska, M., Firms' adoption of international standards: One size fits all?, Journal of Policy Modeling 35 (2), 2013, pp. 289-306.

[5] Morikawa, M., and Morrison, J., Who Develops ISO Standards? A Survey of Participation in ISO's International Standards Development Processes, Pacific Institute for Studies in Development, Environment, and Security, 2004.

[6] Coallier, F., Standards, agility, and engineering., Computer, 40 (9), 2007, pp. 100102.

[7] IEEE Standards Association, Develop Standards, website, Available from https://standards.ieee.org/develop/overview.html.

[8] Coleman, G., and O'Connor, R.V., Investigating software process in practice: A grounded theory perspective, Journal of Systems and Software, 81 (5), 2008, pp. 772-784.

[9] O'Connor, R. V., and Coleman, R., Ignoring Best Practice: Why Irish Software SMEs are Rejecting CMMI and ISO 9000, Australasian Journal of Information Systems, 16 (1), 2009.

[10] O'Connor, R. V., and Coleman, G,. An investigation of barriers to the adoption of software process best practice models, ACIS 2007 Proceedings, 2007.

[11] Laporte, C. Y., Alexandre, S. and O'Connor, R.V., A software engineering lifecycle standard for very small enterprises, Software Process Improvement. Springer Berlin Heidelberg, 2008, pp. 129-141.

[12] Basri, S. , and O'Connor, R.V., Understanding the perception of very small software companies towards the adoption of process standards, Systems, Software and Services Process Improvement, Springer Berlin Heidelberg, 2010. 153-164.

[13] O'Connor, R.V., Evaluating management sentiment towards ISO/IEC 29110 in very small software development companies, Software Process Improvement and Capability Determination. Springer Berlin Heidelberg, 2012. 277-281.

[14] O'Connor, R. V., Basri, S., and Coleman, G., Exploring managerial commitment towards SPI in small and very small enterprises, Systems, Software and Services Process Improvement. Springer Berlin Heidelberg, 2010. 268-279.

[15] Sanchez-Gordon, M.L., O'Connor, R.V. and Colomo, R., Evaluating VSEs viewpoint and sentiment towards the ISO/IEC 29110 standard: A two country grounded theory study, Software Process Improvement and Capability Determination. Springer International Publishing, 2015. 114-127.

[16] International Organization for Standardization, How does ISO develop standards?, websote availabe from http://www.iso.org/iso/home/standards_development.htm.

[17] O'Connor, R. V. and Laporte, C. Y., An Innovative Approach to the Development of an International Software Process Lifecycle Standard for Very Small Entities, International Journal of Information Technology and the Systems Approach, Vol. 7, No. 1, pp. 1-22, 2014.

[18] Laporte, C. Y., O'Connor, R. V., Fanumy, G., International Systems and Software Engineering Standards for Very Small Entities, CrossTalk, The Journal of Defense Software Engineering, Vol. 26, No. 3, May/June 2013, pp. 28 - 33. 
[19] Laporte, C.Y., O'Connor, R.V., Garcia Paucar, L. and Gerancon B., An Innovative Approach in Developing Standard Professionals by Involving Software Engineering Students in Implementing and Improving International Standards, Journal of the Society for Standards Professionals, Vol. 67, No. 2, 2015.

[20] Morales-Trujillo, M.E., Oktaba, H. and Piattini, M., The making of an omg standard, Computer Standards \& Interfaces 42, 2015, pp. 84-94.

[21] O'Connor, R., Deploying a Software Process Lifecycle Standard in Very Small Companies, In Khosrow-Pour, M. (Ed.), Encyclopedia of Information Science and Technology, Chapter 73, pp. 762-772, IGI Global, 2014.

[22] Laporte, C. Y. and O'Connor, R. V., Designing Systems Engineering Profiles for VSEs, Proceedings 14th International Conference on Software Process Improvement and Capability dEtermination (SPICE 2014), CCIS Vol. 477, Springer-Verlag, 2014.

[23] Laporte, C. Y., and ßO'Connor, R.V., Systems and software engineering standards for very small entities: implementation and initial results, Proceedings of 9th International Conference on the Quality of Information and Communications Technology (QUATIC 2014), 2014.

[24] Clarke, P., O'Connor, R.V. and Yilmaz, M., A hierarchy of SPI activities for software SMEs: results from ISO/IEC 12207-based SPI assessments, Software Process Improvement and Capability Determination, Springer Berlin Heidelberg, 2012. pp. 6274.

[25] O'Connor, R. V. and Basri, S., Understanding the Role of Knowledge Management in Software Development: A Case Study in Very Small Companies, International Journal of Systems and Service-Oriented Engineering, Vol. 4, No. 1, pp. 39-52, 2014.

[26] Krishnamurthy, A., and O'Connor, R.V., Using ISO/IEC 12207 to analyze open source software development processes: an E-learning case study, Software Process Improvement and Capability Determination. Springer Berlin Heidelberg, 2013. Pp. 107-119.

[27] De Vries, H. J. Standardization: A business approach to the role of national standardization organizations. Springer Science \& Business Media, 2013.

[28] Choi, D. G. and de Vries, H.J., Standardization as emerging content in technology education at all levels of education, International Journal of Technology and Design Education 21 (1), 2011, pp. 111-135.

\section{ABOUT THE AUTHOR}

Prof. Rory V. O'Connor is an Associate Professor of Software Engineering at Dublin City University where he is currently serving as the Head of the School of Computing. He is also a Senior Researcher with Lero, the Irish Software Research Centre and is also Ireland's Head of Delegation to the ISO/IEC JCT1/SC7 and ISO/IEC JCT1/SC40 standardization groups. His research interests are centered on the processes and standards whereby software-intensive systems are designed, implemented and managed. $\mathrm{He}$ is currently the Editor in Chief of the journal Computer Standards and Interfaces. He can be contacted via the website http://roryoconnor.com/ or email to rory.oconnor@dcu.ie. 